\title{
Allergen reduction measures in houses of allergic asthmatic patients: effects of air-cleaners and allergen-impermeable mattress covers
}

\author{
S. van der Heide, H.F. Kauffman, A.E.J. Dubois, J.G.R. de Monchy
}

\begin{abstract}
Allergen reduction measures in houses of allergic asthmatic patients: effects of aircleaners and allergen-impermeable mattress covers. S. van der Heide, H.F. Kauffman, A.E.J. Dubois, J.G.R. de Monchy. @ERS Journals Ltd 1997.

ABSTRACT: Recommendations for allergen avoidance or allergen reduction measures play an important part in the treatment of allergic asthmatic patients. The purpose of this study was to test recently developed air-cleaners with respect to their capacity to capture airborne allergen particles and to improve clinical parameters of asthmatic patients sensitized to aeroallergens.

Forty five allergic asthmatic patients were studied in a double-blind procedure for 6 months. The patients were divided into three groups of 15 patients. In Group 1 , the intervention consisted of the application of active air-cleaners in living-rooms and bedrooms. In Group 2, placebo air-cleaners were used in combination with allergen-impermeable mattress covers. In Group 3, the same intervention was performed as in Group 2 but with active air-cleaners. Allergen levels in mattress and floor dust were measured before, and 3 and 6 months after the interventions. After 6 months, the air-cleaners were dismantled and the filters were analysed for the amount of dust collected and allergen content. Immunological and lung function parameters were measured before, and 3 and 6 months after the interventions.

Considerable amounts of airborne dust and allergenic particles were captured in the filters of the air-cleaners. Up to the $18.9 \mathrm{~g}$ of dust, $4,513 \mathrm{ng}$ of house dust mite allergen, Der $p$ 1, and 50,000 $\mathrm{mU}$ of cat allergen, Fel $d$ 1, (in houses with cats) were collected by air-cleaners in living-rooms. Only in Group 3 (in which both active air-cleaners and mattress covers were used) was a small (less than 1 doubling dose) but statistically significant improvement of provocative concentration of histamine causing a $20 \%$ fall in forced expiratory volume in one second (PC20) observed (from 5.96 to $9.02 \mathrm{mg} \cdot \mathrm{mL}^{-1}$ ). The amount of dust and house dust mite allergen collected in the filters was significantly correlated with an improvement of peak flow variation.

In combination with other allergen avoidance measures, the examined air-cleaners can contribute to diminished allergen exposure and improvement of airway hyperresponsiveness in asthmatic patients.

Eur Respir J 1997; 10: 1217-1223.
\end{abstract}

\author{
Dept of Allergology, Clinic for Internal \\ Medicine, University Hospital Groningen, \\ Groningen, The Netherlands. \\ Correspondence: S. van der Heide \\ Dept of Allergology \\ Clinic for Internal Medicine \\ University Hospital Groningen \\ Hanzeplein 1 \\ 9713 GZ Groningen \\ The Netherlands
}

Keywords: Air filtration

airway hyperresponsiveness

allergens

house dust mites

mattress covers

Received: May 301996

Accepted after revision December 61996

The study was financially supported by a grant from Philips Domestic Appliances \& Personal Care, Groningen, The Netherlands.
Exposure to indoor allergens is an important cause of allergic reactions in sensitized asthmatic patients [1]. In up to $80 \%$ of sensitized asthmatic children, exposure to house dust mite (HDM) allergens contributes significantly to their clinical problems [2-4]. It has been shown that significant changes in allergen exposure may influence airway hyperresponsiveness, which is a principal feature of asthmatic patients [5, 6]. HDM sensitized asthmatic children residing for prolonged periods at high altitude, show clear improvements in airway hyperresponsiveness $[7,8]$. Sensitized asthmatic patients challenged in hospital with an allergen-containing aerosol usually develop a bronchial obstructive reaction $[9,10]$. When lung function has returned to baseline levels, airway hyperresponsiveness often remains increased for some time, during which patients demonstrate heightened responses to nonspecific stimuli, such as cold air, smoke etc. [9, 11]. Recommendations for allergen avoidance measures, therefore, play an important part in the treatment of allergic patients [1, 12].

Several allergen avoidance programmes have been introduced in recent decades [12-14]. Besides the removal of allergen sources (domestic animals, old mattresses, old carpets) it has been shown that the introduction of smooth floor coverings (nontextile), low levels of indoor air humidity, increased air ventilation, and the application of allergen-impermeable mattress and pillow covers, are measures which can contribute to diminished exposure to HDM allergens, and which may be accompanied by improvement of clinical symptoms [15-17].

A number of studies examining the efficacy of aircleaners in houses of asthmatic patients, have been published in the last 20 yrs [18-21]. In these studies, small beneficial effects on peak flow, peak flow variation or 
clinical symptoms have been claimed. The relationship between changes observed in clinical parameters and the air-cleaners, however, is often questionable, since changes in allergen exposure were not usually determined [22].

The development of new air-cleaners, which combine different filtration techniques with high and constant capacity of air-filtration and a low turbulence of room air, has prompted further studies of the contribution of air-cleaners to allergen avoidance programmes in houses of allergic and asthmatic patients.

\section{Materials and methods}

\section{Patients}

Forty five patients with mild asthma, a history of airway hyperresponsiveness and a positive intradermal skin test to at least Dermatophagoides pteronyssinus, were asked to participate in the study. The patients' clinical characteristics and sensitization to different aeroallergens are summarized in table 1 . In addition to HDM, most patients were sensitized to other aeroallergens; of the 45 patients, 22 were sensitized to HDM, pollen and pets. All patients had increased airway hyperresponsiveness to histamine, as defined by a provocative concentration of histamine causing a $20 \%$ fall in forced expiratory volume in one second $\left(\mathrm{PC}_{20}\right) \leq 32 \mathrm{mg} \cdot \mathrm{mL}^{-1}$. All of the patients were nonsmokers. Characteristics of the 45 houses are summarized in table 2 . The presence of cats/dogs in the houses was independent of allergic sensitization to these animals. The presence of domestic animals was not related to smooth floor coverings in living-rooms or in bedrooms.

Although the patients were nonsmokers (exclusion criterion), regular cigarette smoking by co-residents (passive smoking) occurred in $33 \%$ of the 45 houses. The distribution of the domestic characteristics, as mentioned in table 2, was comparable in the three patient groups.

Table 1. - Clinical characteristics of the three groups of asthmatic patients with a positive skin test to at least HDM

\begin{tabular}{lccc}
\hline & Group 1 & Group 2 & Group 3 \\
\hline Patients n & 15 & 15 & 15 \\
Age yrs & 32 & 32 & 33 \\
& $(18-35)$ & $(19-45)$ & $(18-45)$ \\
Sex F/M & $8 / 7$ & $10 / 5$ & $10 / 5$ \\
FEV1 \% pred & 95 & 93 & 93 \\
& $(69-119)$ & $(75-107)$ & $(78-124)$ \\
PC20 histamine mg.mL -1 & 6.06 & 8.44 & 7.31 \\
& $(0.08-32)$ & $(0.48-32)$ & $(0.15-124)$ \\
Positive skin test (HEWS $\geq 0.7)$ & & \\
HDM alone n & 5 & 3 & 3 \\
HDM + pollen n & 10 & 10 & 11 \\
HDM + pets n & 8 & 9 & 9 \\
HDM + pets + pollen $\mathrm{n}$ & 7 & 7 & 8 \\
\hline
\end{tabular}

The values in parentheses are ranges. F: female; M: male; FEV1: forced expiratory volume in one second; \% pred: percentage of predicted value; $\mathrm{PC} 20$ : provocative concentration producing a $20 \%$ fall in FEV1; HDM: house dust mite; HEWS: histamine equivalent wheal size.
Table 2. - Characteristics of the 45 houses (total group and the three subgroups)

Total Group 1 Group 2 Group 3

\begin{tabular}{llccc}
\hline $\begin{array}{c}\text { Presence of } \\
\text { domestic animals }\end{array}$ & 15 & 6 & 4 & 5 \\
$\begin{array}{c}\text { Cigarette smoking } \\
\text { by co-residents }\end{array}$ & 15 & 5 & 6 & 4 \\
$\begin{array}{c}\text { Textile floor } \\
\text { covering in LR }\end{array}$ & 36 & 12 & 12 & 12 \\
$\begin{array}{c}\text { Textile floor } \\
\text { covering in BR }\end{array}$ & 26 & 8 & 9 & 9 \\
\hline
\end{tabular}

LR: living-rooms; BR: bedrooms.

Eighty percent of the patients used inhaled corticosteroids as maintenance therapy. No significant differences in the use of inhaled steroids were observed between the three patient groups or during the study. Changes in use of $\beta$-agonists, antihistamines and cromoglycate/ nedocromil were not recorded. All patients gave their written informed consent for the study, which was approved by the Medical Ethics Committee of University Hospital Groningen.

\section{Study design}

The domestic and clinical effects of applying air-filtration equipment and/or allergen-impermeable mattress and pillow covers in the houses of asthmatic patients for 6 months were studied in a double-blind, randomized manner in three parallel groups of 15 patients each. The treatment in each group consisted of: Group 1, active air-cleaners in living-rooms and bedrooms; Group 2, placebo air cleaners plus mattress and pillow covers; and Group 3, active air cleaners plus mattress and pillow covers.

The allocation of the 45 patients into the three groups was performed with a computer using a minimization program, with stratification by airway hyperresponsiveness (PC20 histamine) and by the type of floor covering (smooth/textile) in the bedroom. Allocation to Groups 2 and 3 was, therefore, random and comparisons of these two groups were carried out in a double-blind fashion.

Before and 3 and 6 months after intervention, the patients visited the out-patient clinic for spirometric evaluation. Venous blood was also collected for measurement of total serum immunoglobulin $\mathrm{E}$ (IgE) and eosinophil count. Before each visit, patients recorded peak flow values every morning and evening throughout 1 week. On the same occasions, dust samples from floors (living-room and bedroom) and from the mattress were collected by vacuum-cleaning. The inclusion period lasted 1 year. The months in which the three visits for clinical evaluation occurred ( $\mathrm{t}=0,3$ and 6 months), were similar for the three patient groups.

\section{Intervention materials}

Air-cleaners from Philips DAP (Groningen, The Netherlands) were used in living-rooms and bedrooms (Model HR 4320 and HR 4330, respectively). In the air-cleaners, the air was filtered first by a coarse Pre-filter, followed 
by a Rota-filter, in which small dust particles were captured by rotation at high speed. The last filter consisted of a high efficiency particulate air (HEPA)-type filter (American Society of Heating, Refrigeration and Air condition Equipment (ASHRAE) 95\%), filtering $70 \%$ of $0.3 \mu \mathrm{m}$ particles and $95 \%$ of $1.0 \mu \mathrm{m}$ particles. The models used were prototypes. Placebo air-cleaners could not be distinguished from active air-cleaners, but they contained no filter devices.

Special allergen-impermeable mattress and pillowcases ( $\mathrm{ACb}^{\mathrm{TM}}$; Allergy Control Products Inc., Ridgefield, USA) were applied to mattresses and pillows in the bedrooms of patients of Groups 2 and 3 by a nurse. During the study, the covers were not removed from mattresses and pillows.

\section{Spirometry and measurement of airway hyperrespon- siveness}

Lung function (forced expiratory volume in one second (FEV1) and vital capacity (VC)) was tested using a water-sealed spirometer. Nonspecific airway hyperresponsiveness was measured by stepwise inhalation of increasing concentrations of histamine solution for $30 \mathrm{~s}$, until a decrease in FEV1 of $20 \%$ or more was observed [10]. From the fall in FEV1, the PC20 histamine was calculated by linear intrapolation. In five patients without a histamine threshold after 3 or 6 months, the PC20 histamine was set to $33 \mathrm{mg} \cdot \mathrm{mL}^{-1}$ for analysis of the results.

All medication (except inhaled steroids) was stopped before the tests: $\beta$-agonists and ipratropium bromide $12 \mathrm{~h}$, and cromoglycate and antihistamines $72 \mathrm{~h}$ before the histamine provocation. No patients received oral steroids or long-acting bronchodilators.

\section{Skin testing and IgE measurements}

Before inclusion in the study, patients were subjected to intracutaneous skin testing with a panel of five common inhalant allergens (ALK-Benelux, Groningen, The Netherlands). In addition to $D$. pteronyssinus, patients were tested with allergenic extracts from cat, dog, grass pollen and tree pollen. The results of the skin tests were expressed in histamine equivalent wheal size (HEWS), which was calculated by dividing the wheal size obtained with the allergen extract by the wheal size of a standard histamine solution. A skin test with a HEWS of $\geq 0.7$ was regarded as positive. At the start of the study, and after 3 and 6 months, serum total IgE was measured by Pharmacia-IgE-EIA (Pharmacia Diagnostics, Sweden).

\section{Collection and extraction of dust samples}

At 0,3 and 6 months, dust samples from floors of bedrooms and living-rooms were collected by vacuumcleaning (type T560, $1100 \mathrm{~W}$, with a double filtering system; Philips, The Netherlands); the entire floor area was sampled and the dust from each room was collected in separate bags. For each room, the floor area sampled was recorded. Mattress dust was collected by vacuumcleaning the whole mattress, using an appropriate device
(ALK-Benelux, Denmark). Vacuum-cleaning of the mattresses occurred with the mattress covers in place. After sieving (pore size $0.35 \mathrm{~mm}$ ), the amount of fine dust was weighed and a $10 \%(\mathrm{w} / \mathrm{v})$ extract in $0.01 \mathrm{M} \mathrm{NH}_{4} \mathrm{HCO}_{3}$ buffer was obtained by overnight rotation at $4^{\circ} \mathrm{C}$. The dust from mattresses was extracted without sieving. All extracts were centrifuged and the supernatants stored at $-18^{\circ} \mathrm{C}$ until measurement of HDM allergen and cat allergen was carried out.

\section{Recovery of dust from air-cleaner filters}

At the end of the study, the air-cleaners were dismantled and the filters were analysed with regard to the amount of dust collected, and the HDM allergen Der $p$ 1 , and cat allergen, Fel $d 1$, content. The Rota and HEPA-type filters were extracted with $600 \mathrm{~mL} 0.01 \mathrm{M}$ $\mathrm{NH}_{4} \mathrm{HCO}_{3}$ buffer. The extracts were freeze-dried and stored at $-20^{\circ} \mathrm{C}$. Before use, the freeze-dried material was reconstituted at a concentration of $50 \mathrm{mg} \cdot \mathrm{mL}^{-1}$ in a phosphate buffered saline solution ( $\mathrm{pH} 7.4$ ), containing $2 \%$ bovine serum albumin (BSA). Dust from Prefilters was collected by vacuum-cleaning and extracted in the same way as mattress dust samples.

\section{Detection of HDM and cat allergens in dust extracts}

The HDM allergen, Der $p$ 1, and the cat allergen, Fel $d 1$, were measured as described previously [6]. Briefly, monoclonal antibodies to Der $p 1$ and Fel $d 1$ were coupled to microtitre plates (Greiner, Germany) by incubation of the wells with an appropriate dilution of the monoclonal antibody overnight at $4^{\circ} \mathrm{C}$. After washing the wells, the dust extracts were added to the wells in an appropriate dilution and incubated for $2 \mathrm{~h}$ at room temperature. The wells were washed and then incubated for $3 \mathrm{~h}$ with IgE positive pool sera (radioallergosorbent test (RAST) class $\geq 4$ ), which consisted of 25 sera of HDM allergic or cat allergic patients. The amount of human $\operatorname{IgE}$ bound to the allergen immobilized to the solid phase was then measured according to the instructions for the Phadezym-RAST kit (Pharmacia Diagnostics, Uppsala, Sweden). Reference house dust extracts, which were calibrated for the content of $\operatorname{Der} p 1$ and $\mathrm{Fel}$ $d 1$ were used in serial dilutions for calculation of the allergen content in dust samples.

\section{Statistical analysis}

Statistical analysis was performed with the Statistical Package for the Social Sciences (SPSS)-package for PCs (SPSS Inc., Chicago, USA). Differences between groups were analysed by Student's t-test if the data were distributed normally (as measured by the KolmogorovSmirnov test). When the data were not distributed normally, they were log-transformed and the results were expressed as geometric means. Otherwise, differences were analysed by the Wilcoxon nonparametric test. Correlations between variables were expressed by Pearson's correlation coefficient. Differences with p-values of less than 0.05 were considered significant. The influence of 
different environmental factors (presence of domestic animals, type of floor covering, changes in allergen concentrations in several dust samples, smoking behaviour, amount of filter dust captured) and patient characteristics (age, gender, allergic sensitization, FEV1 as \% predicted, use of inhaled steroids, treatment group) on the changes of airway hyperresponsiveness $(\triangle \mathrm{PC} 20$ histamine) during the study was assessed in a stepwise multiple linear regression model.

\section{Results}

Influence of mattress covers on dust and allergen recovery

Both the amount of collected dust and the amount of HDM allergen, Der $p$ 1, diminished significantly in mattresses covered with allergen-impermeable cases, as is demonstrated in figure $1 \mathrm{a}$ and $\mathrm{b}$, respectively.

At the start of the study (baseline level), the amount of dust collected and Der $p 1$ concentration were comparable (Groups 2 and 3 (with mattress cover) versus Group 1 (without mattress cover)). The amount of dust
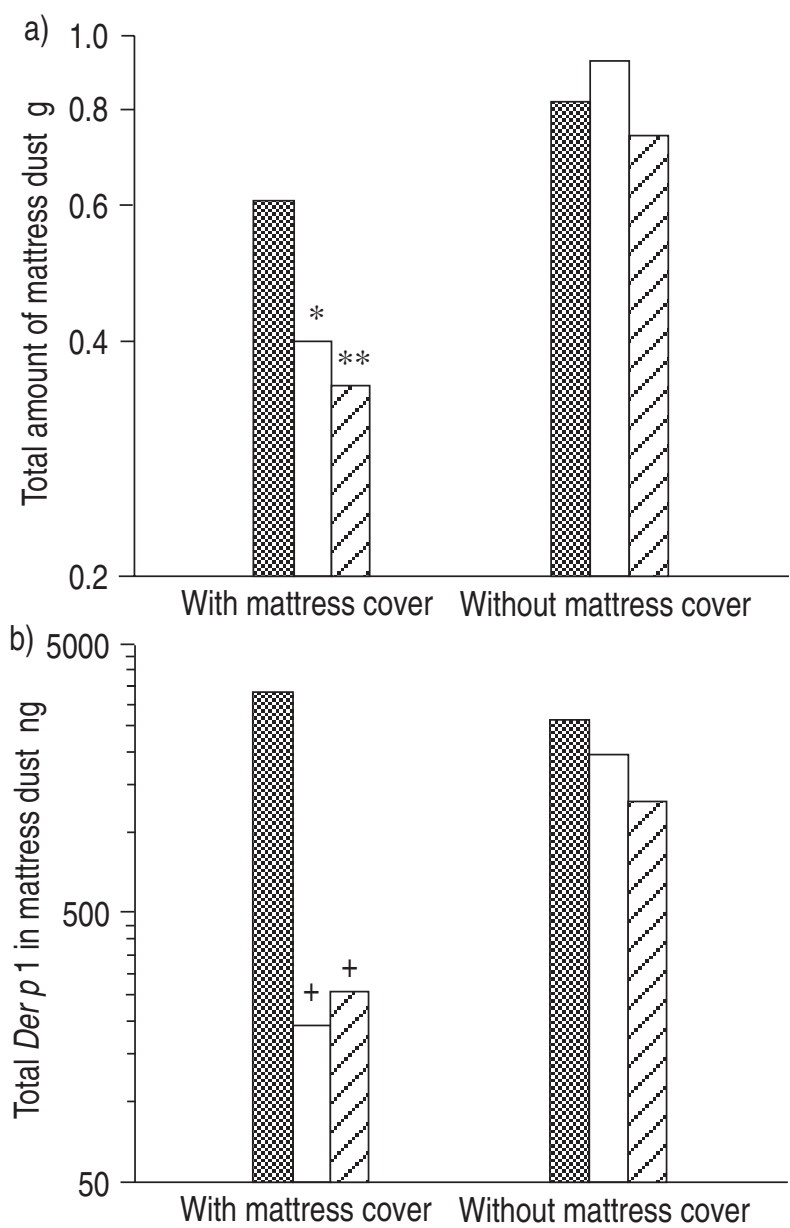

Fig. 1. - Changes in: a) amount of mattress dust collected; and b) concentration of mite allergen, Der $p$ 1, after intervention with allergen-impermeable mattress covers. With mattress covers: Groups 2

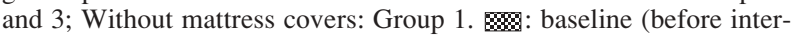
vention); $\square$ : after 3 months; $\square$ : after 6 months. Geometric mean values are presented. $*: \mathrm{p}<0.05 ; * *: \mathrm{p}<0.01 ;{ }^{+}: \mathrm{p}<0.001$, all compared with baseline (Student's t-test). collected and, especially, the total quantity of Der $p 1$ decreased strongly in Groups 2 and 3 (with mattresses covered) compared to Group 1 (no mattress covers).

\section{Amount of dust captured by the filters}

A large variation in the amount of airborne dust collected was found between the different houses as is shown in table 3 . The amount of dust captured in the different filters (or total filter dust) from active air-cleaners (Groups 1 and 3) was not related to type of floor covering or to the amount of floor dust collected. In living-rooms, 2.42 and $1.91 \mathrm{~g}$ of floor dust were collected before and 6 months after intervention, respectively. For the bedrooms, the values were 1.32 and $1.08 \mathrm{~g}$ dust.

Air turbulence was expected to cause more airborne dust particles in rooms with smooth coverings. However, smooth floors contained less dust than textile floor coverings, which may explain why no differences in levels of airborne dust were found.

Passive smoking of cigarettes clearly influenced the amount of dust in the HEPA-type filter from air-cleaners in living-rooms but not in bedrooms, as is demonstrated in table 4 . It is obvious that the small smoke particles are preferentially captured by the HEPA-type filters, whereas the pores of the Pre-filters are too large to retain these small particles. The effects of smoking behaviour is only observed in living-rooms, which is in accordance with the fact that the frequency of cigarette smoking is generally higher in living-rooms than in bedrooms.

Table 3. - Total amounts of house dust and house dust mite allergen, Der $p 1$ captured in the different filters of active air-cleaners (Group 1 and 3 ) from livingrooms (LR) and bedrooms (BR)

\begin{tabular}{lcccccrr}
\hline & & \multicolumn{3}{c}{ Mean } & \multicolumn{2}{c}{ Min } & \multicolumn{2}{c}{ Max } \\
& & $\begin{array}{c}\text { Dust } \\
\mathrm{g}\end{array}$ & $\begin{array}{c}\text { Der } \\
\text { ng }\end{array}$ & $\begin{array}{c}\text { Dust } \\
\mathrm{g}\end{array}$ & $\begin{array}{c}\text { Der } p \\
\text { ng }\end{array}$ & $\begin{array}{c}\text { Dust } \\
\mathrm{g}\end{array}$ & $\begin{array}{c}\text { Der } 1 \\
\text { ng }\end{array}$ \\
\hline Pre-filter & LR & 1.91 & 520 & 0.33 & 2 & 7.14 & 4180 \\
& BR & 1.19 & 490 & 0.91 & 1 & 5.10 & 2423 \\
Rota-filter & LR & 0.74 & 87 & 0.10 & 1 & 1.76 & 351 \\
& BR & 0.83 & 63 & 0.15 & 1 & 1.93 & 138 \\
HEPA-filter & LR & 4.99 & 55 & 0.70 & $<1$ & 13.20 & 186 \\
& BR & 2.14 & 50 & 0.72 & $<1$ & 6.28 & 155 \\
Total & LR & 6.77 & 511 & 1.04 & 3 & 18.95 & 4513 \\
& BR & 2.39 & 485 & 0.91 & 2 & 13.82 & 2670 \\
\hline
\end{tabular}

HEPA: high efficiency particulate air.

Table 4. - Effect of smoking pattern on the amount of dust collected in filters from air-cleaners in living rooms (LR) and bedrooms (BR)

\begin{tabular}{llccc}
\hline & & $\begin{array}{c}\text { Smoking } \\
(\mathrm{n}=15)\end{array}$ & $\begin{array}{c}\text { No smoking } \\
(\mathrm{n}=30)\end{array}$ & $\mathrm{p}$-values \\
\hline Pre-filter & LR & $3.45 \pm 0.39$ & $2.46 \pm 0.37$ & $\mathrm{NS}$ \\
Pre-filter & BR & $1.77 \pm 0.41$ & $1.67 \pm 0.25$ & $\mathrm{NS}$ \\
HEPA-filter & LR & $8.17 \pm 0.91$ & $3.40 \pm 0.514$ & $\mathrm{p}<0.001$ \\
HEPA-filter & BR & $2.38 \pm 0.98$ & $2.01 \pm 0.15$ & $\mathrm{NS}$ \\
All filters & LR & $11.85 \pm 0.89$ & $7.08 \pm 1.16$ & $\mathrm{p}<0.05$ \\
All filters & BR & $3.26 \pm 1.28$ & $3.04 \pm 0.31$ & $\mathrm{NS}$ \\
\hline
\end{tabular}

Values are presented as mean \pm SEM. HEPA: high efficiency particulate air; Ns: nonsignificant. 
Unexpectedly, the placebo air-cleaners also captured dust and allergens because of the presence of a coarse endfilter, which was added in order to prevent unblinding of patients and investigators. Eight of these end-filters of the placebo air-cleaners were available for analysis; the amount of dust captured in end-filters from air-cleaners in living-rooms was $3.17 \mathrm{~g}$ (mean), and in bedrooms was $2.12 \mathrm{~g}$.

\section{Amount of allergens captured by the filters}

HDM allergen, Der $p$ 1, was captured in reasonable amounts by the filters as is shown in table 3 . Most $\operatorname{Der} p 1$ was found in the coarse Pre-filter, followed by smaller quantities in the Rota-filter. In $30 \%$ of the extracts of the HEPA-type filters, no HDM allergen could be detected, whereas all Pre- and Rota-filters contained detectable levels of the HDM allergen, Der $p 1$.

The concentration of $\operatorname{Der} p 1$ in floor dust was not related to the amount of filter-captured HDM allergen. In living-rooms, the concentration of Der $p 1$ in floor dust was 797 and $420 \mathrm{ng} \cdot \mathrm{g}^{-1}$ (geometric means) for $\mathrm{t}=0$ and $\mathrm{t}=6$ months, respectively $(\mathrm{p}<0.01)$, whereas the concentration was 1,122 and $739 \mathrm{ng} \cdot \mathrm{g}^{-1}$ for bedrooms $(\mathrm{t}=0$ and $\mathrm{t}=6$ months, respectively; $\mathrm{p}<0.01$ ). No differences between the three groups were observed. The coarse endfilters of eight sham air-cleaners contained an average of 390 and $285 \mathrm{ng}$ Der $p 1$ for living-rooms and bedrooms, respectively.

Cat allergen could be detected in all filter classes when cats were present. In the 10 houses with cats, all HEPAtype filters contained cat allergen, Fel $d 1$ (range 5,352$48,690 \mathrm{mU}$ in living-rooms and $1,000-33,840 \mathrm{mU}$ in bedrooms). In the houses without cats, the amount of cat allergen, Fel $d$, in the HEPA-type filters varied from undetectable (in $40 \%$ of the rooms) to $5,081 \mathrm{mU}$ in living-rooms, and from undetectable (36\% of the rooms) to $1,562 \mathrm{mU}$ in bedrooms. In Pre-filters and Rota-filters, similar differences in the amount of cat allergen, Fel $d$ 1, captured were observed as in HEPA-type filters, again depending on the presence of cats.

\section{Changes in airway hyperresponsiveness (PC20 hista- mine) during the study}

In the total group of patients, a statistically significant improvement of airway hyperresponsiveness (higher PC20 histamine) was found after 6 months, as is shown in figure 2. However, the improvement was less than 1 doubling dose. When analysed by group, this improvement of PC20 histamine was found only in Group 3, the group with active air-cleaners in their houses and allergen-impermeable mattress and pillow covers in the bedroom, whereas a trend to improvement was observed in Group 2, with mattress covers but placebo air-cleaners.

Multiple regression analysis was performed to study the factors that contributed significantly to the occurrence of the improvement of airway hyperresponsiveness between the first and third measurement. From this analysis, it appeared that $32 \%$ of the variance of the change in airway hyperresponsiveness ( $\mathrm{PC} 20$ histamine) between 0 and 6 months could be explained by the following four variables: treatment group $(\beta=0.4039 ; \mathrm{p}=0.005) ; \Delta$ Der

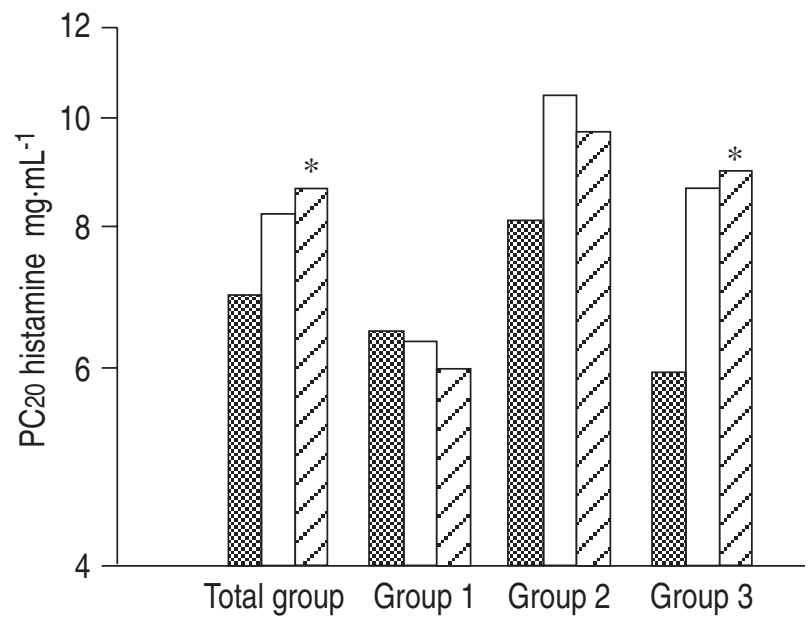

Fig. 2. - Changes in airway hyperresponsiveness (PC20 histamine) after intervention with air-cleaners and/or allergen-impermeable mattress covers. Group 1: active air-cleaners only; Group 2: allergenimpermeable mattress covers and placebo air-cleaners; Group 3; allergen-impermeable mattress covers and active air-cleaners. 8 : baseline (before intervention); $\square$ : after 3 months; $\square$ : after 6 months. Geometric mean values are presented on a logarithmic scale. PC20: provocative concentration producing a $20 \%$ fall in forced expiratory volume in one second. $*$ : $\mathrm{p}<0.05$, compared with baseline (Wilcoxon test)

$p 1$ in mattress dust between 0 and 6 months $(\beta=0.4976$; $\mathrm{p}=0.002)$; floor covering in living-room $(\beta=-0.3393$; $\mathrm{p}=0.014)$; and presence of cats $/ \operatorname{dogs}(\beta=0.3661 ; \mathrm{p}=0.020)$.

It can be concluded that most improvement of $\mathrm{PC}_{20}$ histamine was found in patients who: were included in Group 3; had textile floor covering in the living-room; possessed domestic animals; and experienced the largest decrease in concentration of HDM allergen, Der $p 1$, in mattress dust. Changes in PC20 histamine were not influenced by the use of inhaled steroids. Evaluation of effects of air-filtration on clinical variables due to exposure to cat allergen was not possible because only four patients who were sensitized to cats did, in fact, own a cat. In addition, these four patients were also highly sensitized to HDM allergens, and two of the four patients were also sensitized to grass pollen.

\section{Changes in peak flow and peak flow variation during the study}

Morning and evening peak flow values did not change significantly during the study. On all occasions and in all three groups, the morning peak flow value was significantly lower than the evening value. Peak flow variation (the difference between peak flow value in the morning and peak flow value in the evening) showed a trend to lower values in Groups 2 and 3 but the differences were not statistically significant. The observed variations in peak flow were rather small (5.0 and 4.6\% during the first and the third measurement, respectively), and fell within the range for healthy individuals. Additional analysis of the changes of peak flow variation between 0 and 6 months showed that a decrease in peak flow variation was significantly correlated with: the amount of dust collected in Pre-filters from air-cleaners in living-rooms $(r=0.431 ; p=0.005)$; the total amount of dust captured in the three filters from the air-cleaners 
Table 5. - Changes in number of eosinophils in peripheral blood during the study, after different interventions

\begin{tabular}{|c|c|c|c|c|}
\hline & \multicolumn{4}{|c|}{ Eosinophils cells $\mu \mathrm{L}^{-1}$} \\
\hline & Total & Group 1 & Group 2 & Group 3 \\
\hline Baseline & 307 & 303 & 229 & 368 \\
\hline After 3 months & $248^{+}$ & 285 & $150^{\#}$ & 294 \\
\hline After 6 months & 275 & 349 & $145^{\ddagger}$ & 317 \\
\hline
\end{tabular}

+: $p=0.016$ compared with basal level; \#: $p=0.048$ compared with Group 1 and 0.022 with Group 3; $\mathrm{p}=0.032$ compared with Group 1 and 0.0014 with Group 3.

in living-rooms ( $r=0.356 ; \mathrm{p}=0.017)$; and the amount of HDM allergen, Der $p$ 1, captured in the Pre-filters ( $\mathrm{r}=$ $0.292 ; \mathrm{p}=0.047$ ).

\section{Changes in immunological parameters}

In the group of patients as a whole, the number of eosinophils in peripheral blood decreased significantly after 3 months, as is demonstrated in table 5 .

In Group 2 (allergen-impermeable mattress covers and sham air-cleaners) and in Group 3 (allergen-impermeable mattress covers and active air-cleaners) a tendency to lower numbers of eosinophils was found after the intervention. The changes, however, were not statistically significant. Serum total $\mathrm{IgE}$ showed a decrease only in Group 2 (baseline level $354 \mathrm{kU} \cdot \mathrm{L}^{-1}$ (geometric mean), and after 6 months $282 \mathrm{kU} \cdot \mathrm{L}^{-1} ; \mathrm{p}=0.002$ ); whereas, no statistically significant differences were observed in Groups 1 and 3 or in the total group of patients.

The changes observed could not be explained by differences in use of inhaled steroids.

\section{Discussion}

Asthma is a common disease worldwide. In many asthmatic patients, sensitization to aeroallergens contributes significantly to their clinical problems, and there is growing evidence that the prevalence of asthma is increasing [1, 23, 24]. It is generally accepted that recommendations for allergen avoidance play an important role in the treatment of these patients $[1,12]$. Of the allergen reduction measures available, the application of special mattress covers has been shown to be effective in reducing the exposure to HDM allergens from mattress dust in several studies $[16,17,25]$. In an Australian study, however, no long lasting ( $>4$ weeks) effect of mattress covers on the level of the HDM allergen, Der $p 1$, in mattress dust was found and no clinical effects were observed [26]. In contrast, a study by EHNERT et al. [17] in Germany showed a considerable improvement in airway hyperresponsiveness. An important difference between these two studies was the age of the participating patients: children almost exclusively sensitized to house dust mites were studied in the German report, whereas adult patients with allergic sensitization to many inhalant allergens took part in the Australian study. In the latter, exposure to allergens other than house dust mites may have interfered with clinical improvements expected from HDM allergen reduction measures.

In the present study, the application of allergen-impermeable mattress and pillow covers in the bedrooms of patients had an obvious effect on the level of the HDM allergen, $\operatorname{Der} p 1$, in mattress dust, showing a substantial decrease in the concentration of this allergen (fig. 1b). A small (less than 1 doubling dose) but statistically significant improvement of airway hyperresponsiveness was observed after 6 months only in the group of patients where, in addition to mattress covers, active air-cleaners were also employed (fig. 2), suggesting that the combination of different allergen reduction measures was more effective than each single measure alone. In this study, we were unable to show a significant clinical effect of allergen-impermeable mattress covers alone.

The air cleaners in the present study clearly showed the capacity to capture substantial amounts of airborne dust particles and airborne allergens (tables 3 and 5). Both HDM allergen, Der $p$ 1, and cat allergen, Fel d 1, could easily be detected in Pre-filters and Rota-filters. When cats were present in the house, cat allergen, Fel $d$ 1, was always found in the HEPA-type filters, whereas the presence of the HDM allergen, $\operatorname{Der} p$ 1, in these HEPA-type filters was less frequent. The fact that cat allergen is bound to smaller dust particles than HDM allergens may be responsible for the differences observed in filter distribution of these allergens. It was not possible to demonstrate clinical improvement due to removal of airborne cat allergens because of the low number $(n=4)$ of patients with cats who were also cat allergic.

This is one of the first reports demonstrating definite amounts of dust and allergen particles captured by high efficiency air-cleaners. The fact that the placebo (sham) air-cleaners also captured dust and allergen particles has probably reduced differences between active and placebo air-cleaners in this study. The noise produced by the counters may have been responsible for the observation that many air-cleaners were not maximally operative during the study, which may also have reduced the effect of this intervention.

The number of studies in which environmental and clinical effects of application of air-cleaners has been investigated is limited and they show inconsistent results [18-21]. A clear relationship between reduction of clinical parameters of asthma and the use of air-cleaners is absent. In these studies, patient selection is often imprecise, whereas in other studies objective clinical parameters were not measured [22].

It is also clear that the application of air-cleaners alone will not be sufficient for effective reduction of exposure to indoor allergens, which is probably true, however, for most allergen avoidance measures [26-28]. In allergic asthmatic patients with a broad sensitization to inhalant allergens, a combination of different allergen reduction measures is generally necessary to obtain optimal improvement of clinical symptoms or airway parameters (PC20 histamine, peak flow variation, medication requirement). The observation that the air-cleaners studied clearly captured relevant indoor allergens and contributed to a small but significant improvement of airway hyperresponsiveness and decrease of peak flow variation, indicates the need for further studies to investigate optimal conditions, in which such air-cleaners can help to reduce exposure to inhalant indoor allergens in such a way that allergic and asthmatic patients may obtain maximal clinical benefit [29]. 


\begin{abstract}
Acknowledgements: The skilful assistance of $\mathrm{H}$. Beverdam and L. Koese in collecting the data is greatly acknowledged. The cell line for the monoclonal antibodies against the house dust mite allergen, Der $p 1$, and the monoclonal antibody against cat allergen, Fel $d$ 1, were a generous gift from R. Aalberse (Central Laboratory of the Dutch Red Cross Blood Transfusion Service, Amsterdam, The Netherlands). The allergen-impermeable mattress and pillow covers $\left(\mathrm{ACb}^{\mathrm{TM}}\right)$ were kindly donated by Meditex BV, Rossum, The Netherlands.
\end{abstract}

\section{References}

1. Platts-Mills TA, Thomas WR, Aalberse RC, Vervloet D, Chapman MD. Dust mite allergens and asthma: report of a second international workshop. J Allergy Clin Immunol 1992; 89: 1046-1060.

2. Sporik R, Holgate ST, Platts-Mills TA, Cogswell JJ. Exposure to house dust mite allergen (Der $p$ 1) and the development of asthma in childhood. A prospective study. N Engl J Med 1990; 323: 502-507.

3. Sporik R, Holgate ST, Cogswell JJ. Natural history of asthma in childhood: a birth cohort study. Arch Dis Child 1991; 66: 1050-1053.

4. Meijer GG, Postma DS, Van der Heide S, et al. Exogenous stimuli and circadian peak expiratory flow variation in allergic asthmatic children. Am J Respir Crit Care Med 1996; 153: 237-242.

5. Marks GB, Tovey ER, Green W, Shearer M. The effect of changes in house dust mite allergen exposure on the severity of asthma. Clin Exp Allergy 1995; 25: 114118.

6. Van der Heide S, De Monchy JGR, De Vries K, Bruggink TM, Kauffman HF. Seasonal variation in airway hyperresponsiveness and natural exposure to house dust mite allergens in patients with asthma. J Allergy Clin Immunol 1994; 93: 470-475.

7. Kerrebijn KF. Endogenous factors in childhood CNSLD: methodological aspects in population studies. In: Orie NGM, Van der Lende R, eds. Bronchitis. III. Proceedings of the Third International Symposium on Bronchitis, The Netherlands, 1969. Assen, Royal Van Gorcum, 1970: pp. 38-48.

8. Peroni DG, Boner AL, Vallone G, Antolini I, Warner JO. Effective allergen avoidance at high altitude reduces allergen-induced bronchial hyperresponsiveness. Am J Respir Crit Care Med 1994; 149: 1442-1446.

9. Vries K. de, Goei JT, Booij-Noord H, Orie NGM. Changes during 24 hours in lung function and histamine hyperreactivity of the bronchial tree in asthmatic and chronic bronchitis patients. Int Arch Allergy Appl Immunol 1962; 20: 93-101.

10. De Monchy JG, Kauffman HF, Venge P, et al. Bronchoalveolar eosinophilia during allergen-induced late asthmatic reactions. Am Rev Respir Dis 1985; 131: 373376.

11. Aalbers R, Kauffman HF, Vrugt B, et al. Bronchial lavage and bronchoalveolar lavage in allergen-induced single early and dual asthmatic responders. Am Rev Respir Dis 1993; 147: 76-81.
12. Chapman MD, Heymann PW, Sporik RB, Platts-Mills TA. Monitoring allergen exposure in asthma: new treatment strategies. Allergy 1995; 50: 29-33.

13. Bessot JC, de Blay F, Pauli G. From allergen sources to reduction of allergen exposure. Eur Respir J 1994; 7: 392-397.

14. Colloff MJ, Ayres J, Carswell F, et al. The control of allergens of dust mites and domestic pets: a position paper. Clin Exp Allergy 1992; 22 (Suppl. 2): 1-28.

15. Korsgaard J. Preventive measures in house dust allergy. Am Rev Respir Dis 1982; 125: 80-84.

16. Wickman M, Nordvall SL, Pershagen G, Korsgaard J, Johansen N, Sundell J. Mite allergens during 18 months of intervention. Allergy 1994; 49: 114-119.

17. Ehnert B, Lau-Schadendorf S, Weber A, Buettner P, Schou C, Wahn U. Reducing domestic exposure to dust mite allergen reduces bronchial hyperreactivity in sensitive children with asthma. J Allergy Clin Immunol 1992; 90: 135-138.

18. Antonicelli L, Bilo MB, Pucci S, Schou C, Bonifazi F. Efficacy of an air-cleaning device equipped with a high efficiency particulate air filter in house dust mite respiratory allergy. Allergy 1991; 46: 594-600.

19. Warburton CJ, Niven RM, Pickering CA, Fletcher AM, Hepworth J, Francis HC. Domiciliary air filtration units, symptoms and lung function in atopic asthmatics. Respir Med 1994; 88: 771-776.

20. Reisman RE, Mauriello PM, Davis GB, Georgitis JW, DeMasi JM. A double-blind study of the effectiveness of a high efficiency particulate air (HEPA) filter in the treatment of patients with perennial allergic rhinitis and asthma. J Allergy Clin Immunol 1990; 85: 1050-1057.

21. Fischer M, Knauer S, Petzold D, Sonntag HG. Filtration of airborne allergens in various households. Zentralbl Hyg Umweltmed 1994; 196: 258-269.

22. Fox RW. Air-cleaners: a review. J Allergy Clin Immunol 1994; 94: 413-416.

23. Peat JK, Tovey E, Toelle BG, et al. House dust mite allergens: a major risk factor for childhood asthma in Australia. Am J Respir Crit Care Med 1996; 153: 141-146.

24. Peat JK, van den Berg RH, Green WF, Mellis CM, Leeder SR, Woolcock AJ. Changing prevalence of asthma in Australian children. BMJ 1994; 308: 1591-1596.

25. Owen S, Morganstern M, Hepworth J, Woodcock AA. Control of house dust mite antigen in bedding. Lancet 1990; 335: 396-397.

26. Marks GB, Tovey ER, Green W, Shearer M, Salome $\mathrm{CM}$, Woolcock AJ. House dust mite allergen avoidance: a randomized, controlled trial of surface chemical treatment and encasement of bedding. Clin Exp Allergy 1994; 24: $1078-1083$.

27. Kniest FM, Young E, Van Praag MC, et al. Clinical evaluation of a double-blind dust mite avoidance trial with mite-allergic rhinitic patients. Clin Exp Allergy 1991; 21: 39-47.

28. Hayden ML, Rose G, Diduch KB, et al. Benzyl benzoate moist powder: investigation of acaricidal activity in cultures and reduction of dust mite allergens in carpets. J Allergy Clin Immunol 1992; 89: 536-545.

29. Spector SL, Nicklas RA. Practice parameters for the diagnosis and treatment of asthma. J Allergy Clin Immunol 1995; 96(5, part 2): 717-767. 